\title{
PENERAPAN MODEL PEMBELAJARAN KONSTRUKTIVISME UNTUK MENINGKATKAN KEMAMPUAN MENGIDENTIFIKASI KARAKTERISTIK INTI ATOM DAN RADIOAKTIFITAS PADA PELAJARAN FISIKA INTI DI KELAS XII IPA 3 SMA NEGERI 12 MEDAN T.A 2013/2014
}

\author{
Marlon Sihole \\ SMA Negeri 12 Medan \\ marlone.sihole@gmail.com
}

\begin{abstract}
ABSTRAK
Penerapan model pembelajaran konstruktivisme untuk meningkatkan kemampuan mengindentifikasi karakteristik inti atom dan radioaktifitas telah dilakukan. Penelitian ini dilakukan untuk mengetahui kemampuan siswa dalam mempelajari inti atom dan radioaktivitas. Subjek penelitian sebanyak 44 orang siswa. Alat pengumpulan data yang digunakan adalah observasi yang dilakukan pada siswa.Dari hasil penelitian dan analisis data bahwa terdapat peningkatan kemampuan siswa mengidentifikasi karakteristik inti atom dan radioaktifitas mulai dari siklus I pertemuan 1 dan 2 sampai dengan siklus II pertemuan 1 dan 2 . Dimana pada siklus pertama, terdapat 11 orang siswa yang sudah tuntas mencapai tingkat ketuntasan kemampuan siswa mengidentifikasi karakteristik inti atom dan radioaktifitas atau presentase skornya mencapai $25 \%$ sedangakan 33 orang siswa mengidentifikasi karakteristik inti atom dan radioaktifitas belum tuntas mencapai tingkat ketuntasan criteria ketuntasan minimal, atau persentase skornya $75 \%$. Sedangkan pada siklus kedua $100 \%$ siswa sudah tuntas. Berdasarkan hasil refleksi dapat disimpulkan bahwa menggunakan model konstruktivisme pada pelajaran fisika kompetensi dasar mengidentifikasi karakteristik inti atom dan radioaktivitas di kelas XII IPA 3 SMA Negeri 12 Medan baik secara individual maupun klasikal.
\end{abstract}

Kata Kunci: Model Pembelajaran Konstruktivisme, PTK, Hasil Belajar 


\section{PENDAHULUAN}

Mata pelajaran Fisika termasuk dalam salah satu mata pelajaran yang sangat dibenci atau tidak disenangi oleh siswa. Oleh karena itu, banyak siswa SMA yang mendapatkan nilai yang rendah. Salah satu pembelajaran dalam fisika adalah pembelajaran Fisika Inti merupakan pembelajaran ilmu - ilmu Fisika yang membahas inti atom. Reaksi yang terjadi pada inti atom dapat menghasilkan energi yang sangat besar. Energi yang terjadi ini dapat digunakan untuk membinasakan seperti halnya bom atom, tetapi lebih baik lagi jika digunakan untuk kelangsungan dan kesejahteraan umat manusia. Untuk dapat mengetahui dan mendapatkan energi dari proses yang terjadi pada inti atom, maka harus lebih dulu mengetahui lebih dalam tentang apa saja yang ada pada inti atom.

Berdasarkan pengalaman penulis, permasalahan yang ditemukan dalam pelajaran fisika adalah kesulitan siswa dalam memahami materi dalam kurikulum. Pencapaian nilai ujian tingkat kompetensi pada fisika inti cenderung rendah. Sebanyak 10 siswa (25\%) tidak tuntas uji kompetensi pada fisika inti di kelas XII IPA 3 SMA Negeri 12 Medan pada tahun ajaran 2013/2014 dari 44 siswa.

Keberhasilan siswa dalam proses belajar mengajar mata pelajaran fisika sangat ditentukan oleh beberapa faktor. Salah satu diantaranya adalah pembelajaran yang monoton. Hal ini disebabkan karena guru dalam pembelajarannya di kelas kurang mengaitkan dengan pengetahuan yang telah dimiliki siswa dan siswa kurang diberi kesempatan untuk menemukan kembali dan mengkonstruksi sendiri ide-ide fisika atom. Sebagai seorang guru maka perlu tanggap terhadap situasi yang demikian, karena itu perlu memotifasi dan memaksa siswa agar siswa dapat membangun pengetahuan sendiri pengetahuan yang baru, berdasarkan pengetahuan yang telah dimilikinya. Salah satu model pembelajaran yang dapat membangun pengetahuan sendiri adalah model pembelajaran konstruktivisme.

Model konstruktivisme merupakan suatu penjelasan bagaimana siswa belajar dan dapat memahami makna tentang apa yang mereka hadapi. Konstruktivisme merupakan landasan konstektual, dimana pengetahuan dibangun sedikit demi sedikit yang hasilnya diperluas melalui konteks yang terbatas dan dengan tidak tiba-tiba. Dalam model pembelajarankonstruktivisme siswa dituntut untuk mengkonstruksi pengetahuan tentang fisika atom secara aktif, sedangkan peranan guru sendiri hanya sebagai moderator dan fasilitator. Guru sebagai moderator memberikan pengalaman belajar yang memungkinkan siswa bertanggung jawab dalam membuat rancangan proses penelitian. Sedangkan guru sebagai fasilitator menyediakan dan memberikan kegiatan-kegiatan yang merangsang keingin tahuan siswa, membantu mereka untuk megekspresikan gagasan gagasannya dan mengkomunikasikan ide ilmiah mereka. Menyediakan sarana dan merangsang siswa berfikir 
produktif, dan guru harus menyemangati siswa.

Berdasarkan latar belakang diatas, penulis tertarik untuk melakukan penelitian tindakan kelas (PTK). Adapun yang menjadi tujuan penelitian ini yaitu untuk mengetahui kemampuan siswa dan meningkatkan hasil belajar siswa dalam pokok bahasan inti atom dan radioaktivitas.

\section{Rumusan Masalah}

Berdasarkan batasan masalah di atas maka yang menjadi rumusan masalah dalam penelitian ini adalah :

1) Bagaimanahasil belajar fisika inti di kelas XII IPA3 SMA Negeri 12 Medan sebelum menggunakan model konstrutivisme?.

2) Bagaimana aktivitas dan minat belajar fisika atom di kelas XII IPA3 SMA Negeri 12 Medan untuk mengembangkan pengetahuannya denganmenggunakan model pembelajaran konstruktivisme?.

3) Bagaimana hasil belajar fisika inti siswa kelas XII IPA3SMA Negeri 12 Medan setelah menggunakan model pembelajaran konstruktivisme?.

4) Apakah dengan metode konstruktivisme dapat meningkatkan hasil belajar siswa pada pokok bahasan fisika inti?.

\section{Tujuan Penelitian}

1) Mengidentifikasi hasil belajar fisika inti siswa kelas XII IPA3 SMA Negeri 12 Medan pada pokok bahasan fisikka inti sebelum menggunakan model pembelajaran konstruktivisme.

2) Mengetahui aktivitas siswa kelas XII IPA 3 SMA Negeri 12 Medan dalam meningkatkan pemahaman konsep fisika inti dengan menerapkan

metode konstruktivisme.

3) Kendala-kendala apa saja yang dihadapi dengan menerapkan metode konstruktivisme pada pembelajaran fisika inti.

4) Mengidentifikasi hasil belajar siswa kelas XII IPA 3 SMA Negeri 12 Medan dengan menerapkan metode konstruktivisme.

\section{Pengertian Konstruktivisme}

Konstruktivisme menurut Djamarah dan Zein (2006) adalah siswa membangun pengetahuan sendiri pengetahuan yang baru berdasarkan pengetahuan yang telah dimilikinya, pembelajaran dirancang dalam bentuk siswa bekerja, praktik mengerjakan sesuatu, berlatih secara fisik, menulis konsep, mendemonstrasikan, menciptakan gagasan dan sebagainya. Dalam pandangan konstruktivisme, setiap siswa mempunyai peranan dalam menentukan apa yang akan mereka pelajari.

\section{Kerangka Konseptual}

Pembelajaran yang efektif menuntut siswa untuk terlibat secara aktif agar apa yang dipelajari berbekas dalam ingatan siswa. Keaktifan siswa tidak hanya sekedar mengajak siswa terlibat dalam proses belajar mengajar tetapi juga menuntut siswa berpikir, menganalisa dan termotivasi dalam memahami hal-hal yang dipelajarinya secara kreatif. Salah satu metode pembelajaran yang melibatkan siswa secara aktif adalah dengan pendekatan konstruktivisme. Konstruktivisme merupakan landasan berpikir yang digunakan dalam pembelajaran kontekstual, yaitu 
pengetahuan dibangun oleh manusia sedikit demi sedikit yang hasilnya diperluas melalui konteks yang terbatas dan tidak dalam waktu yang singkat.

Konstruktivisme berkembang dari kerja Piaget, Vygotsky, teori-teori pemprosesan informasi, dan teori teori psikologi kognitif yang lain. Penganut konstruktivis berpendapat guru tidak dapat begitu saja memberikan pengetahuan jadi pada siswanya. Agar pengetahuan yang diberikan bermakna, siswa sendirilah yang harus memproses informasi yang diterimanya, menstrukturnya kembali dan mengintegrasikannya dengan pengetahuan yang dimilikinya. Dalam proses ini, guru berperan memberi dukungan dan kesempatan pada siswa untuk menerapkan ide mereka sendiri dan strategi mereka dalam belajar.

Beberapa prinsip teori konstruktivisme menurut Driver (Suparno, 1997:49) sebagai berikut:

1. Pengetahuan dibangun siswa sendiri, baik secara personal maupun sosial.

2. Pengetahuan tidak dapat dipindahkan dari guru ke siswa, kecuali dengan keaktifan siswa sendiri untuk bernalar.

3. Siswa aktif mengkonstruksi terus menerus, sehingga selalu terjadi perubahan konsep ke konsep yang lebih rinci, lengkap, serta sesuaidengan konsep ilmiah.

4. Guru sekedar membantu menyediakan sarana dan situasi agar proses

5. Konstruksi siswa berjalan mulus.

\section{Pemahaman Konsep Fisika Inti}

Menurut Kamus Besar Bahasa Indonesia yang dikeluarkan oleh Pusat Bahasa Departemen Pendidikan Nasional (2004:320) bahwa konsep berarti rancangan yang menunjukkan gambaran mental dari objek, proses, atau apapun yang ada diluar bahasa yang digunakan oleh akal budi untuk memahami halhal lain. Untuk dapat memahami konsep dalam pembelajaran fisika inti, maka harus mengetahui teoriteori yang berhubungan dengan atom, yang secara tidak langsung merupakan dasar informasi mengenai struktur inti. Untuk dapat memahami apa saja yang dipelajari tentang fisika inti itu, maka perlu diketahui partikel yang membangun inti, bentuk ukuran dan gaya inti, stabilitas inti, radioaktivitas, peluruhan unsur radioaktif, waktu paruh dan aktivitas unsur radioaktif, serapan sinar radioaktif, dosis serap dan alat deteksi radiasi, reaksi inti dan energi nuklir, reaktor atom dan bom atom, radio isotop dan penggunaan radioisotop. Komponen-komponen dari pokok bahasan fisika inti ini yang akan dipelajari dan harus dikuasai. Salah satu cara untuk dapat menggampangkan pembelajaran ini, adalah dengan pendekatan konstruktivisme.

\section{Hipotesis Tindakan}

Dari kajian teori dan rumusan masalah maka hipotesis tindakan dalam penelitian ini adalah dengan "Penerapan Model Pembelajaran Konstruktivisme Untuk meningkatkan Kemapuan pada kompetensi dasar Mengidentifikasi Karakteristik Inti Atom dan Radioaktifitas Pada Fisika Inti." 


\section{METODE}

Subjek dalam penelitian tindakan (action research) ini adalah siswa kelas XII IPA3 SMA Negeri 12 Medan. tahun pelajaran 2013/2014yang terdiri dari 44 orang siswa. Objek penelitian ini adalah upaya meningkatkan kemampuan siswa untuk mengidentifikasi karakteristik inti atom dan radioaktifitas pada pelajaran fisika inti melalui pendekatan belajar konstruktivisme di kelas XII IPA3 SMA Negeri 12 Medan tahun pelajaran 2013/2014 yang terdiri dari 44 orang siswa.

Penelitian ini memiliki beberapa tahap pelaksanaan tindakan yang diuraikan dalam dua siklus dengan tahapan (1) Perencanaan, (2) Pelaksanaan Tindakan, (3) Observasi, (4) Refleksi dan (5) Evaluasi, secara lebih rinci prosedur dapat dilihat pada gambar 1 di bawah ini.

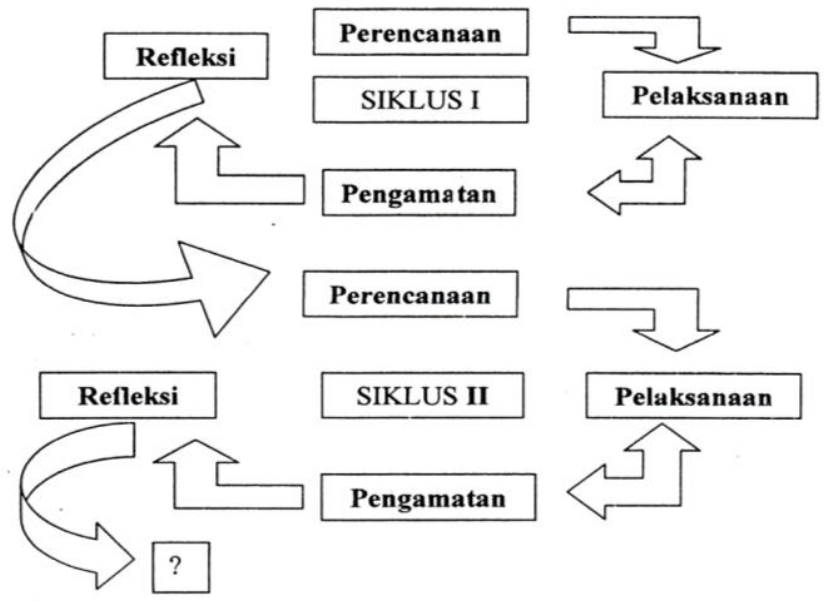

Gambar 1. Skema dalam Penelitian Tindakan Kelas (Arikunto, dkk, 2006) Penelitian ini dilakukan di dalam kelas meliputi kegiatan pelaksanaan PTK berupa tes awal, refleksi awal dan observasi untuk mengidentifikasi permasalahan yang terjadi di kelas. Pada peneltian ini, peneliti dibantu oleh seorang guru IPA dalam mengidentifikasi dan mencari pemecahan masalah pembelajaran dalam mata pelajaran Fisika kelas XII IPA3 SMA Negeri 12 Medan Tahun Ajaran 2013/2014, pelaksanaan dilakukan selama dua siklus.

\section{Teknik Pengumpulan Data}

Responden penelitian dariKelas XII IPA 3 SMA Negeri 12 Medan tahunajaran 2013/2014 Semester genap.

Data yang dikumpulkan dalam penelitian ini meliputi data kuantitatif dan kualitatif. Data yang diperoleh adalah dari hasil pemberian latihan pretes dan postes siklus I dan siklus II. Pretes diberikan untuk mengetahui kemampuan awal siswa sebelum materi diberikan. Sedangkan postes diberikan untuk mengetahui kemampuan siswa setelah diberikannya materi dan dari sinilah diketahui peningkatan terhadap hasil belajar yang ingin diperoleh. Kuantitatif berkenaan dengan kemampuan siswa dalam menyampaikan pendapat mereka akan fisika atom, sedangkan kualitatif berkenaan dengan aktifitas guru dan siswa selama kegiatan pembelajaran berlangsung.

\section{Teknik Analisa Data}

Untuk

mengetahui kemampuansiswa dalam mengidentifikasi karakteristik inti atom dan radioaktivitasberdasarkan observasi dapat digunakan rumus sebagai berikut:

$$
\mathrm{Pi}=\frac{f}{n} \times 10(\text { Sudjana, 2009) }
$$


$\mathrm{Pi}=$ persentase hasil pengamatan $\mathrm{f}=$ jumlah skor hasil observasi

$\mathrm{n}=$ jumlah skor maksimal

Hasil pengukuran ketuntasan kompetensi siswa yang telah ditetapkan olehSMA Negeri 12 Medan untuk mata pelajaran fisika. Tuntas: Apabila siswa dapat menguasai $\geq 75$ dari indikator kemampuan.

Tidak tuntas: Apabila siswa dapat menguasai < 75 dari indikator kemampuan.

Dari uraian di atas dapat diketahui siswa yang kurang, cukup, baik dan sangatbaik dalam pembelajaran dapat diketahui dari persentase perbandingan hasil belajar masing masing individu yaitu dengan ketentuan seperti ditunjukkan pada Tabel 1.

Tabel 1. Kriteria Tingkat

Keberhasilan Siswa.

\begin{tabular}{|c|c|}
\hline Rentang Nilai (\%) & Kriteria \\
\hline $85-100$ & Sangat Baik \\
\hline $70-84$ & Baik \\
\hline $55-69$ & Cukup \\
\hline $0-54$ & Kurang \\
\hline
\end{tabular}

Dan untuk menentukan persentase kemampuan siswa secara klasikal dapat dicari dengan rumus :

$$
\mathrm{P}=\frac{f}{n} \times 100 \%
$$

Dimana:

$\mathrm{P}=$ jumlah persentase siswa yang mengalami perubahan

$\mathrm{f}=$ jumlah siswa yang tuntas

$\mathrm{n}=$ jumlah siswa keseluruhan

Secara individual dikatakan memiliki kemampuan belajar jika Pi dan $\mathrm{P} \geq 65 \%$ dan suatu kelas dikatakan tuntas belajar apabila $\mathrm{P}$ $\geq 80$.

\section{HASIL DAN PEMBAHASAN}

Berdasarkan hasil dari lembar observasi guru terhadap siswa mengenai indikator kemampuan pengetahuan dan keterampilan siswa, maka dapat dilihat persentase skor tingkat kemampuan pengetahuan dan keterampilan siswa yang ditunjukkan pada Tabel 2.

Tabel 2. Persentase Hasil Skor Obeservasi Kemampuan Mengidentifikasi

Karakteristik Inti Atom dan Radioaktifitas Pada Siklus I Pertemuan I

\begin{tabular}{|c|c|c|c|}
\hline \multirow{2}{*}{$\begin{array}{c}\text { Kode } \\
\text { Siswa }\end{array}$} & \multirow{2}{*}{ Skor } & \multicolumn{2}{|c|}{ Siklus 1 Pertemuan I } \\
\cline { 3 - 4 } & \% & Kategori \\
\hline 01 & 16 & 66,70 & Cukup \\
\hline 02 & 17 & 70,00 & Baik \\
\hline 03 & 8 & 33,33 & Cukup \\
\hline 04 & 10 & 41,70 & Kurang \\
\hline 05 & 18 & 75,00 & Baik \\
\hline 06 & 10 & 41,70 & Kurang \\
\hline 07 & 8 & 33,33 & Kurang \\
\hline 08 & 11 & 45,70 & Kurang \\
\hline 09 & 23 & 95,80 & Sangat Baik \\
\hline 10 & 8 & 33,33 & Kurang \\
\hline 11 & 8 & 33,33 & Kurang \\
\hline 12 & 12 & 50,00 & Cukup \\
\hline 13 & 18 & 75,00 & Baik \\
\hline 14 & 15 & 62,50 & Cukup \\
\hline 15 & 15 & 62,50 & Cukup \\
\hline 16 & 17 & 70,80 & Baik \\
\hline 17 & 14 & 58,33 & Kurang \\
\hline 18 & 12 & 50,00 & Kurang \\
\hline 19 & 11 & 45,70 & Kurang \\
\hline 20 & 24 & 100,00 & Sangat Baik \\
\hline 21 & 11 & 45,80 & Kurang \\
\hline 22 & 10 & 41,70 & Kurang \\
\hline 23 & 10 & 41,70 & Kurang \\
\hline 24 & 10 & 41,70 & Kurang \\
\hline 25 & 12 & 50,00 & Kurang \\
\hline 26 & 21 & 87,50 & Sangat Baik \\
\hline 27 & 11 & 45,80 & Kurang \\
\hline 28 & 11 & 45,80 & Kurang \\
\hline 29 & 12 & 50,00 & Kurang \\
\hline 30 & 14 & 58,30 & Cukup \\
\hline 31 & 23 & 95,80 & Sangat Baik \\
\hline 32 & 8 & 33,33 & Kurang \\
\hline 33 & 8 & 33,33 & Kurang \\
\hline 34 & 12 & 50,00 & Kurang \\
\hline & & & \\
\hline
\end{tabular}


Vol. 3, No. 2, Mei 2015

\begin{tabular}{|c|c|c|c|}
\hline 35 & 18 & 75,00 & Baik \\
\hline 36 & 15 & 62,50 & Cukup \\
\hline 37 & 15 & 62,50 & Cukup \\
\hline 38 & 17 & 70,80 & Baik \\
\hline 39 & 14 & 58,33 & Kurang \\
\hline 40 & 12 & 50,00 & Kurang \\
\hline 41 & 11 & 45,70 & Kurang \\
\hline 42 & 24 & 100,00 & Sangat Baik \\
\hline 43 & 11 & 45,80 & Kurang \\
\hline 44 & 10 & 41,70 & Kurang \\
\hline & \multicolumn{3}{|c|}{605} \\
\hline & \multicolumn{4}{|c|}{13,75} \\
\hline
\end{tabular}

Dari Tabel 2 di atas pada siklus

I pertemuan I dengan jumlah siswa sebanyak 44 orang, diperoleh data bahwa 25 orang siswa (57\%) tingkat kemampuan mengidentifikasi karakteristik inti atom dan radioaktivitas pada fisika inti tergolong kurang, 8 orang siswa (18 $\%$ tingkat kemampuan mengidentifikasi karakteristik inti atom dan radioaktivitas pada fisika inti tergolong cukup, 6 orang siswa (14 \%) kemampuan mengidentifikasi karakteristik inti atom dan radioaktivitas pada fisika inti tergolong baik dan 5 orang siswa (11 \%) yang tingkat kemampuan mengidentifikasi karakteristik inti atom dan radioaktivitas pada fisika inti tergolong sangat baik, yang ditunjukkan pada Tabel 3.

Tabel 3. Persentase Hasil Skor Obeservasi Kemampuan Siswa Mengidentifikasi Karakteristik Inti Atom dan Radioaktifitas Pada Fisika Inti Pada Siklus I Pertemuan 2

\begin{tabular}{|c|c|c|c|}
\hline Kode & \multirow{2}{*}{\begin{tabular}{c}
\multirow{2}{*}{ Skor } \\
\cline { 3 - 4 }
\end{tabular}} & \multicolumn{2}{|c|}{ Siklus 1 pertemuan II } \\
\hline 01 & 17 & 70,80 & Kategori \\
\hline 02 & 17 & 70,80 & Baik \\
\hline 03 & 10 & 41,70 & Baik \\
\hline 04 & 10 & 41,70 & Kurang \\
\hline
\end{tabular}

\begin{tabular}{|c|c|c|c|}
\hline 05 & 18 & 75,00 & Baik \\
\hline 06 & 10 & 41,70 & Kurang \\
\hline 07 & 9 & 37,50 & Kurang \\
\hline 08 & 11 & 45,70 & Kurang \\
\hline 09 & 23 & 95,80 & Sangat Baik \\
\hline 10 & 9 & 37,50 & Kurang \\
\hline 11 & 9 & 37,50 & Kurang \\
\hline 12 & 12 & 50,00 & Kurang \\
\hline 13 & 18 & 75,00 & Baik \\
\hline 14 & 17 & 70,80 & Baik \\
\hline 15 & 15 & 62,50 & Cukup \\
\hline 16 & 17 & 70,80 & Baik \\
\hline 17 & 14 & 58,33 & Kurang \\
\hline 18 & 12 & 50,00 & Kurang \\
\hline 19 & 11 & 45,70 & Kurang \\
\hline 20 & 24 & 100,00 & Sangat Baik \\
\hline 21 & 11 & 45,80 & Kurang \\
\hline 22 & 10 & 41,70 & Kurang \\
\hline 23 & 10 & 41,70 & Kurang \\
\hline 24 & 10 & 41,70 & Kurang \\
\hline 25 & 12 & 50,00 & Kurang \\
\hline 26 & 21 & 87,50 & Sangat Baik \\
\hline 27 & 11 & 45,80 & Kurang \\
\hline 28 & 11 & 45,80 & Kurang \\
\hline 29 & 12 & 50,00 & Kurang \\
\hline 30 & 14 & 58,33 & Cukup \\
\hline 31 & 23 & 95,80 & Sangat Baik \\
\hline 32 & 8 & 33,33 & Kurang \\
\hline 33 & 8 & 33,33 & Kurang \\
\hline 34 & 12 & 50,00 & Kurang \\
\hline 35 & 18 & 75,00 & Baik \\
\hline 36 & 15 & 62,50 & Cukup \\
\hline 37 & 15 & 62,50 & Cukup \\
\hline 38 & 17 & 70,80 & Baik \\
\hline 39 & 14 & 58,33 & Kurang \\
\hline 40 & 12 & 50,00 & Kurang \\
\hline 41 & 11 & 45,70 & Kurang \\
\hline 42 & 24 & 100,00 & Sangat Baik \\
\hline 43 & 11 & 45,80 & Kurang \\
\hline 44 & 10 & 41,70 & Kurang \\
\hline & \multicolumn{3}{|c|}{613} \\
\hline & \multicolumn{3}{|c|}{13,93} \\
\hline
\end{tabular}

Berdasarkan Tabel 3 di atas terdapat siswa yang mengalami tingkat kemampuan mengidentifikasi karakteristik inti atom dan radioaktifitas kurang, cukup, baik dan sangat baik. Kemampuan siswa 
Jurnal Inpafi

Vol. 3, No. 2, Mei 2015

kompetensi dasar mengidentifikasi karakteristik inti atom dan radioaktifitas tergolong kurang mencapai hasil persentase skor $33,3 \%$ - $\quad 54,2 \%$. Kemampuan siswa kompetensi dasar mengidentifikasi karakteristik inti atom dan radioaktifitas yang tergolong baik mencapai persentase skor $70,8 \%$ $75 \%$. Kemampuan siswa kompetensi dasar mengidentifikasi karakteristik inti atom dan radioaktifitas yang tergolong sangat baik mencapai persentase skor $87,5 \%$ - 100\%, yang ditunjukkan pada Tabel 4.

Tabel 4. Persentase Hasil Skor Obeservasi Kemampuan Siswa Mengidentifikasi Karakteristik Inti Atom dan Radioaktifitas pada siklus II pertemuan 1

\begin{tabular}{|r|c|c|c|}
\hline \multirow{2}{*}{$\begin{array}{c}\text { Kode } \\
\text { Siswa }\end{array}$} & \multirow{2}{*}{ Skor } & \multicolumn{2}{|c|}{ Siklus I1 Pertemuan I } \\
\cline { 3 - 4 } & & \% & Kategori \\
\hline 01 & 17 & 70,00 & Baik \\
\hline 02 & 17 & 70,00 & Baik \\
\hline 03 & 12 & 50,00 & Kurang \\
\hline 04 & 12 & 50,00 & Kurang \\
\hline 05 & 18 & 75,00 & Baik \\
\hline 06 & 12 & 50,00 & Kurang \\
\hline 07 & 10 & 41,70 & Kurang \\
\hline 08 & 11 & 45,70 & Kurang \\
\hline 09 & 23 & 95,80 & Sangat Baik \\
\hline 10 & 10 & 41,70 & Kurang \\
\hline 11 & 10 & 41,70 & Kurang \\
\hline 12 & 15 & 62,50 & Cukup \\
\hline 13 & 20 & 83,40 & Sangat Baik \\
\hline 14 & 18 & 75,00 & Baik \\
\hline 15 & 18 & 75,00 & Baik \\
\hline 16 & 20 & 83,40 & Sangat Baik \\
\hline 17 & 15 & 62,50 & Cukup \\
\hline 18 & 15 & 62,50 & Cukup \\
\hline 19 & 15 & 62,50 & Cukup \\
\hline 20 & 24 & 100,00 & Sangat Baik \\
\hline 21 & 15 & 62,50 & Cukup \\
\hline 22 & 12 & 50,00 & Kurang \\
\hline 23 & 12 & 50,00 & Kurang \\
\hline 24 & 12 & 50,00 & Kurang \\
\hline 25 & 15 & 62,50 & Cukup \\
\hline & & & \\
\hline
\end{tabular}

\begin{tabular}{|c|c|c|c|}
\hline 26 & 21 & 87,50 & Sangat Baik \\
\hline 27 & 14 & 58,33 & Cukup \\
\hline 28 & 14 & 58,33 & Cukup \\
\hline 29 & 15 & 62,50 & Cukup \\
\hline 30 & 18 & 75,00 & Baik \\
\hline 31 & 23 & 95,80 & Sangat Baik \\
\hline 32 & 10 & 41,70 & Kurang \\
\hline 33 & 10 & 41,70 & Kurang \\
\hline 34 & 15 & 62,50 & Cukup \\
\hline 35 & 21 & 87,50 & Sangat Baik \\
\hline 36 & 18 & 75,00 & Baik \\
\hline 37 & 18 & 75,00 & Baik \\
\hline 38 & 21 & 87,50 & Sangat Baik \\
\hline 39 & 15 & 62,50 & Cukup \\
\hline 40 & 15 & 62,50 & Cukup \\
\hline 41 & 12 & 50,00 & Kurang \\
\hline 42 & 24 & 100,00 & Sangat Baik \\
\hline 43 & 12 & 50,00 & Kurang \\
\hline 44 & 12 & 50,00 & Kurang \\
\hline & \multicolumn{3}{|c|}{690} \\
\hline & \multicolumn{3}{|c}{15,68} \\
\hline
\end{tabular}

Dilihat dari Tabel 4 di atas terdapat siswa yang mengalami tingkat kemampuan mengidentifikasi karakteristik inti atom dan radioaktivitas kurang, cukup, baik dan sangat baik. Kemampuan mengidentifikasi karakteristik inti atom dan radioaktivitas tergolong kurang mencapai hasil persentase skor 33,3\% - 54,2\%. Kemampuan mengidentifikasi karakteristik inti atom dan radioaktivitas yang tergolong baik mencapai persentase skor 70,8\% - 75\%. Kemampuan mengidentifikasi karakteristik inti atom dan radioaktivitas yang tergolong sangat baik mencapai persentase skor $87,5 \%-100 \%$, yang ditunjukkan pada Tabel 5 . 
Vol. 3, No. 2, Mei 2015

\section{Tabel 5. Persentase Hasil Skor Obeservasi Kemampuan Pada Mengidentifikasi Karakteristik Inti Atom dan Radioaktifitas Siklus Pertemuan 2}

\begin{tabular}{|c|c|c|c|}
\hline \multirow{2}{*}{$\begin{array}{l}\text { Kode } \\
\text { Siswa }\end{array}$} & \multirow{2}{*}{ Skor } & \multicolumn{2}{|c|}{ Siklus II pertemuan II } \\
\hline & & $\%$ & Kategori \\
\hline 01 & 18 & 75,00 & Baik \\
\hline 02 & 18 & 75,00 & Baik \\
\hline 03 & 17 & 70,00 & Baik \\
\hline 04 & 17 & 70,00 & Baik \\
\hline 05 & 18 & 75,00 & Baik \\
\hline 06 & 17 & 70,00 & Baik \\
\hline 07 & 17 & 70,00 & Baik \\
\hline 08 & 17 & 70,00 & Baik \\
\hline 09 & 23 & 95,80 & Sangat Baik \\
\hline 10 & 17 & 62,50 & Baik \\
\hline 11 & 17 & 62,50 & Baik \\
\hline 12 & 18 & 75,00 & Baik \\
\hline 13 & 20 & 83,40 & Sangat Baik \\
\hline 14 & 20 & 83,40 & Sangat Baik \\
\hline 15 & 20 & 83,40 & Sangat Baik \\
\hline 16 & 20 & 83,40 & Sangat Baik \\
\hline 17 & 18 & 75,00 & Baik \\
\hline 18 & 18 & 75,00 & Baik \\
\hline 19 & 18 & 75,00 & Baik \\
\hline 20 & 24 & 100,00 & Sangat Baik \\
\hline 21 & 18 & 75,00 & Baik \\
\hline 22 & 18 & 75,00 & Baik \\
\hline 23 & 18 & 75,00 & Baik \\
\hline 24 & 18 & 75,00 & Baik \\
\hline 25 & 18 & 75,00 & Baik \\
\hline 26 & 21 & 87,50 & Sangat Baik \\
\hline 27 & 17 & 70,00 & Baik \\
\hline 28 & 17 & 70,00 & Baik \\
\hline 29 & 18 & 75,00 & Baik \\
\hline 30 & 18 & 75,00 & Baik \\
\hline 31 & 23 & 95,80 & Sangat Baik \\
\hline 32 & 17 & 62,50 & Baik \\
\hline 33 & 17 & 62,50 & Baik \\
\hline 34 & 18 & 75,00 & Baik \\
\hline 35 & 21 & 87,50 & Sangat Baik \\
\hline 36 & 21 & 87,50 & Sangat Baik \\
\hline 37 & 21 & 87,50 & Sangat Baik \\
\hline 38 & 21 & 87,50 & Sangat Baik \\
\hline 39 & 18 & 75,00 & Baik \\
\hline 40 & 18 & 75,00 & Baik \\
\hline 41 & 17 & 70,00 & Baik \\
\hline
\end{tabular}

\begin{tabular}{|c|c|c|c|}
\hline 42 & 24 & 100,00 & Sangat Baik \\
\hline 43 & 17 & 70,00 & Baik \\
\hline 44 & 17 & 70,00 & Baik \\
\hline & \multicolumn{3}{|c|}{$\mathbf{8 2 3}$} \\
\hline & \multicolumn{3}{|c|}{18,70} \\
\hline
\end{tabular}

Berdasarkan Tabel 5 di atas terdapat siswa yang mengalami tingkat kemampuan mengidentifikasi karakteristik inti atom dan radioaktifitas kurang, cukup, baik dan sangat baik. Kemampuan mengidentifikasi karakteristik inti atom dan radioaktifitas tergolong kurang mencapai hasil persentase skor $33,3 \%$ - 54,2\%. Kemampuan siswa mengidentifikasi karakteristik inti atom dan radioaktifitas yang tergolong baik mencapai persentase skor 70,8\% - 75\%. Kemampuan siswa mengidentifikasi karakteristik inti atom dan radioaktifitas yang tergolong sangat baik mencapai persentase skor $87,5 \%-100 \%$.

Setelah melakukan penelitian selama 2 siklus (4 pertemuan) dapat disimpulkan bahwa penerapan model konstruktivisme pada pelajaran fisika kompetensi dasar mengidentifikasi karakteristik inti atom dan radioaktifitas, dapat meningkatkan kemampuan siswa-siswa mengidentifikasi karakteristik inti atom dan radioaktifitas baik secara individual maupun secara klasikal. Hal ini juga dapat dilihat dari hasil data rekapitulasi mulai dari siklus I sampai dengan siklus II serta hal ini juga dapat dilihat dari keaktifan siswa di dalam kelas seperti siswa dapat berkomunikasi satu dengan lainnya dalam memecahkan permasalahan yang diberikan oleh guru dan dari hal ini terlihat juga antuas siswa dalam bekerja 
berkelompok serta saling diskusi sehingga dapat memunculkan keakraban antar siswa. Hal ini sejalan seperti yang telah dilakukan oleh Hapsari (2011) yang menyatakan bahwa siswa yang kesulitan dapat termotivasi belajar dengan penerapan model konstruktivisme, dikarenakan model ini membangun komunikasi antar siswa, sehingga siswa dapat saling membantu dalam menyelesaikan permasalahan yang diberikan oleh guru.

\section{KESIMPULAN}

1. Penggunaan konstruktivisme model meningkatkan kemampuan siswa siswa mengidentifikasi karakteristik inti atom dan radioaktifitas di kelas XII IPA3 SMA Negeri 12 Medan Tahun Ajaran 2013 / 2014.

2. Penelitian dibagi menjadi II siklus tiap siklus terdiri dari 2 pertemuan, peneliti menggunakan analisis data observasi.

3. Dari hasil analisis data dapat disimpulkan bahwa terdapat peningkatan kemampuan siswa mengidentifikasi karakteristik inti atom dan radioaktifitas mulai dari siklus I pertemuan 1, pertemuan 2 sampai dengan siklus II pertemuan 1 dan 2 .

\section{DAFTAR PUSTAKA}

Arikunto, Suharjono dan Supriadi, 2006, Penelitian Tindakan Kelas, Jakarta. Bumi Aksara.

Djamarah, B., S., dan Zein, A., 2006, Stategi Belajar Mengajar, Jakarta: PT Rineka Cipta.

Sudjana, 2005, Metode Statistika, PT.

Tarsito, Bandung.
Suparno, Paul. 1997. Filsafat Kontruktivitik dalam Pendidikan. Yogyakarta: Kanisius.

Hapsari, T., S., 2011, Penerapan Model Pembelajaran Konstruktivisme untuk Meningkatkan Hasil Belajar IPA, Jurnal Pendidikan Penabur, 34-45 